\title{
Therapeutic Efficacy of Subgingivally Delivered Doxycycline Hyclate as an Adjunct to Non-surgical Treatment of Chronic Periodontitis
}

\author{
Vikas Deo ${ }^{1}$, Salman Ansari², Sunita Mandia ${ }^{3}$, Manohar Bhongade ${ }^{2}$ \\ 'Department of Periodontology and Implantology, Government Dental College, Jaipur, India. \\ ${ }^{2}$ Department of Periodontology and Implantology, Sharad Pawar Dental College, Wardha, India. \\ ${ }^{3}$ Private practitioner and at present in Jaipur, India.
}

\author{
Corresponding Author: \\ Vikas Deo \\ 224, Padmawati B, Kings Road, 302019, Jaipur \\ India \\ Phone: +919950991918 \\ Fax: +911512230316 \\ E-mail: drvikas81@yahoo.com
}

\begin{abstract}
Objectives: Locally used doxycycline has been shown to concentrate in crevicular fluid and demonstrates a wide spectrum of activity against the periodontal pathogens. The aim of the present clinical study was to evaluate the efficacy of doxycyline hyclate $10 \%$ as an adjunct to scaling and root planing in the treatment of chronic periodontitis.

Material and Methods: 60 systemically healthy, chronic periodontitis patients were included in the study. Randomized clinical trial was performed over the 6 month period. Test group was treated by scaling and root planing followed by local delivery of doxycycline hyclate $10 \%$, while the control group was treated by scaling and root planing along with placebo.

Results: Significantly greater $(\mathrm{P}<0.001)$ reduction in the mean probing pocket depth was demonstrated in the test group $(3.03 \pm 0.92 \mathrm{~mm})$ when compared with the control group $(2.3 \pm 0.65 \mathrm{~mm})$. When the differences in clinical attachment level gain for the test group $(2.0 \pm 0.64 \mathrm{~mm})$ versus control group $(1.13 \pm 1.07 \mathrm{~mm})$ were analyzed by Student's unpaired t-test, test group showed statistically greater clinical attachment level gain $(0.87 \pm 0.22 \mathrm{~mm}, \mathrm{P}<0.001)$.

Conclusions: From the analysis of the results it can be concluded that the use of doxycyline hyclate $10 \%$ as an adjunct to scaling and root planing provides more favourable and statistically significant $(\mathrm{P}<0.001)$ reductions in probing pocket depth and gains in clinical attachment level compared to scaling and root planing alone.
\end{abstract}

Keywords: doxycycline hyclate; periodontal diseases; chronic periodontitis; periodontium; periodontal pocket.

Accepted for publication: 20 December 2010

To cite this article:

Deo V, Ansari S, Mandia S, Bhongade B. Therapeutic Efficacy of Subgingivally Delivered Doxycycline Hyclate as an Adjunct to Non-surgical Treatment of Chronic Periodontitis.

J Oral Maxillofac Res 2011 (Jan-Mar);2(1):e3

URL: http://www.ejomr.org/JOMR/archives/2011/1/e3/v2n1e3ht.pdf

doi: $10.5037 /$ jomr.2011.2103 


\section{INTRODUCTION}

The essential goal of periodontal therapy is the successful management of bacterial pathogens to the extent that destruction of the periodontium is arrested. A number of different non-surgical and surgical therapies have been successful in achieving this goal [1-3]. The primary non-surgical approach involves mechanical scaling and root planing (SRP). The beneficial effects of SRP arise from a reduction in the microbial burden in the periodontal pocket, or a shift towards a less pathogenic microflora [4]. However, the efficacy of SRP may be compromised at tooth sites with deep periodontal pockets. Furthermore, the long term success of SRP may be affected by remaining bacterial virulence factors and ineffective personal plaque control.

Several antimicrobial agents have been attempted systemically as an adjunct to mechanical treatment of the periodontal disease. However, the efficacy of these means have been limited by systemic side effects, inability to reach the site of action in adequate concentrations and inability to maintain adequate drug levels for a sufficient time [ $[4, \underline{5}]$. Controlled local delivery of the local antimicrobial agents were subsequently developed that were successful in maintaining the higher concentration of drug in the periodontal pocket for longer periods than systemically delivered methods [].

Many of well controlled trials that evaluated the efficacy of various locally delivered antimicrobial agents have demonstrated better clinical response with doxycycline, when used as an adjunct to SPR $[\underline{7}, \underline{8}]$. Locally used doxycycline has been shown to concentrate in crevicular fluid, successfully eliminate Actinobacillus actinomycetemcomitans and demonstrates a wide spectrum of activity against other suspected periodontal pathogens [9].

Large multicenter human clinical trials $[10,11]$ have shown favourable responses following the use of doxycycline hyclate when delivered subgingivally to human periodontal pocket in a biodegradable controlled release delivery system. However, there is a paucity of literature on the efficacy of doxycyline hyclate in the south Asian population.

Therefore, the aim of the present clinical study was to evaluate the efficacy of doxycyline hyclate $10 \%$ (Atridox $^{\circledR}$, CollaGenx Pharmaceuticals, Inc., Newtown, PA, USA) as an adjunct to scaling and root planing in providing additional benefits compared to scaling and root planing with placebo in the treatment of chronic periodontitis.

\section{MATERIAL AND METHODS}

\section{Study population and design}

Sixty systemically healthy, 25 male and 35 female (aged 30 to 45 years, mean age $=36.8 \pm 4.87$ years), were selected for the study. The subjects had to comply with following criteria:

(i) positive for the diagnosis of generalized chronic periodontitis, as assessed on the basis of clinical attachment level (CAL), measured using a William's graduated periodontal probe $(\mathrm{Hu}-F$ riedy, Chicago, IL, USA),

(ii) good general health,

(iii) negative for hypersensitive to doxycycline,

(iv) negative for the use of any antibiotic or antiinflammatory drugs within the 6 months preceding the beginning of the study.

Pregnant or nursing females were excluded from the study. The subjects were not allowed to take any antibiotics and anti-inflammatory drugs, or chlorhexidine-based mouth rinses, during the entire period of the study.

After the proper examination and diagnosis, all the patients received oral hygiene instructions. Six weeks following the initial therapy, plaque index (PI) and periodontal bleeding index (PBI) were taken to evaluate the oral hygiene status and patient compliance with oral hygiene instructions.

One persistent pocket of $5-7 \mathrm{~mm}$ probing depth surrounding a molar/premolar with a clinically healthy crown was chosen as the experimental site in each patient. An attempt was made to select the sites/teeth identical in terms of severity of the periodontal disease. A comparable number of sites, from the upper and lower dental arches were selected. Patients were divided into two groups: test group (treated by SPR followed by local delivery of doxycycline hyclate $10 \%$ ), and control group (treated by SPR followed by local delivery of a gel containing glycerine as placebo).

Clinical measurements were recorded at 6 weeks following the initial visits (baseline) and again at 6 months. Full mouth supragingival plaque was assessed by using PI [12]. Gingival inflammation was assessed by PBI [13]. The probing measurements recorded for assessment of the results were probing pocket depth (PPD), CAL and gingival recession (REC). These measurements were recorded at 6 sites of each experimental tooth; for later calculations, the mean of 6 sites was taken into consideration. All the probing measurements were made with William's graduated periodontal probe (Hu-Friedy, Chicago, IL, USA).

The purpose and design of this clinical trial was explained to the patients and the informed consent 
was signed by every patient. The study protocol was approved by the ethical committee of Datta Meghe Institute of Medical Sciences, Wardha, India.

\section{Clinical Procedures}

After recording the PI [12] and the PBI [13], probing measurements were carried out. PPD and CAL were measured as the distance from bottom of the pocket to the most apical portion of the gingival margin and the cemento-enamel junction, respectively. The same operator (V.D.), who was blinded to the treatment groups, collected the clinical data.

SRP was done using Hoe scalers and standard Gracey currettes (Hu-Friedy, Chicago, IL, USA) under the local anaesthesia for the test and control group patients.

In the test quadrants, the periodontal pockets were treated by $10 \%$ doxycycline hyclate in bioabsorbable vehicle, which was supplied as an Atrigel $^{\mathrm{B}}$ (CollaGenx Pharmaceuticals, Inc., Newtown PA, USA) delivery system consisting of the two syringes. Syringe A contained the polymer of poly lactic acid DL-Lactide (PLA), dissolved in biocompatible carrier $\mathrm{N}$-methyl-2-pyrrolidone (NMP). Syringe B contained $10 \%$ doxycycline hyclate, which was equivalent to $50 \mathrm{mg}$ of the doxycycline. These two syringes were coupled together just prior to use and was mixed for 100 cycles. Once mixed, the doxycyline hyclate $10 \%$ was allowed to set at room temperature for 15 minutes and then was mixed for another 10 cycles before the use. A 23 gauge blunt cannula was attached to the delivery syringe and gel was expressed into the periodontal pocket. Any overflow of material was gently packed into the pocket with a moist tip of curette in order to speed up coagulation of the polymer. The control sites were treated by SRP followed by local delivery of a gel containing glycerine as placebo.

The patients were recalled at 6 months and the clinical measurements recorded at the baseline were repeated again.

The means and standard deviations of PPD, CAL, REC,
PI and PBI at the baseline and at the 6 months examination were calculated for both groups. The Student's paired t-test was used to compare the data from the baseline to those at the 6 months for each treatment group and between treatment groups. The level of significance was set at $\mathrm{P}<0.05$. All statistical analysis was carried out with the aid of statistical software (SPSS version 12.0, SPSS Inc., Chicago, IL, USA).

\section{RESULTS}

Thirty periodontal pockets (test sites) were treated by SRP combined with subgingival doxycyline hyclate $10 \%$ therapy, while thirty control sites were treated by SRP combined with placebo in a total of 60 chronic periodontitis patients. During the course of the study, the healing was uneventful. No periodontal pocket sites showed adverse reaction to doxycyline hyclate $10 \%$. None of the selected patients dropped out before the termination of study.

At the baseline, PPD was $5.83 \pm 0.53 \mathrm{~mm}$ in the test group and $5.70 \pm 0.65 \mathrm{~mm}$ in the control group. Similarly, mean CAL was $6.50 \pm 0.50 \mathrm{~mm}$ in the test group and $6.53 \pm 0.68 \mathrm{~mm}$ in the control group. The mean REC was $0.66 \pm 0.60 \mathrm{~mm}$ in the test group and $0.83 \pm 0.64 \mathrm{~mm}$ in the control group. At the baseline, no statistically significant differences in any of the investigated parameters were observed between the test and control groups, indicating that the randomization process was effective (Table 1).

The mean PPD reduction was $3.03 \pm 0.92 \mathrm{~mm}$ in the test group and $2.30 \pm 0.65 \mathrm{~mm}$ in the control group at the 6 months examination (Table 1). Student's paired t-test indicated that both groups showed significantly greater mean PPD reduction at the 6 months examination compared to the baseline $(\mathrm{P}<0.001)$ (Table 1). However, significantly greater $(\mathrm{P}=0.001)$ reduction in mean PPD was demonstrated in the test group, showing an additional $0.73 \pm 0.20 \mathrm{~mm}$ PPD reduction (Table 1).

Table 1. Comparison of periodontal probing depth (PPD), clinical attachment level (CAL) and gingival recession (REC) mean values of test and control group patients at different examination intervals

\begin{tabular}{|c|c|c|c|c|c|c|c|c|c|}
\hline \multirow{2}{*}{$\begin{array}{c}\text { Examination } \\
\text { interval }\end{array}$} & \multicolumn{3}{|c|}{ PPD $($ Mean \pm SD $[\mathrm{mm}])$} & \multicolumn{3}{|c|}{ CAL $($ Mean \pm SD $[\mathrm{mm}])$} & \multicolumn{3}{|c|}{$\operatorname{REC}($ Mean \pm SD $[\mathrm{mm}])$} \\
\hline & $\begin{array}{c}\text { Test } \\
\mathbf{n}=\mathbf{3 0}\end{array}$ & $\begin{array}{c}\text { Control } \\
\mathbf{n}=\mathbf{3 0}\end{array}$ & P-value ${ }^{a}$ & $\begin{array}{c}\text { Test } \\
\mathbf{n}=\mathbf{3 0}\end{array}$ & $\begin{array}{c}\text { Control } \\
\mathbf{n}=\mathbf{3 0}\end{array}$ & P-value & $\begin{array}{c}\text { Test } \\
\mathbf{n}=\mathbf{3 0}\end{array}$ & $\begin{array}{c}\text { Control } \\
\mathbf{n}=\mathbf{3 0}\end{array}$ & P-value \\
\hline Baseline & $5.83 \pm 0.53$ & $5.7 \pm 0.65$ & 0.38 & $6.5 \pm 0.5$ & $6.53 \pm 0.68$ & 0.83 & $0.66 \pm 0.6$ & $0.83 \pm 0.64$ & 0.3 \\
\hline At 6 months & $2.8 \pm 0.76$ & $3.4 \pm 0.49$ & $<0.001$ & $4.5 \pm 0.5$ & $5.4 \pm 0.67$ & $<0.001$ & $1.7 \pm 1.11$ & $2.0 \pm 0.9$ & 0.3 \\
\hline Difference & $3.03 \pm 0.92$ & $2.3 \pm 0.65$ & 0.001 & $2.0 \pm 0.64$ & $1.13 \pm 1.07$ & $<0.001$ & $1.03 \pm 1.15$ & $1.16 \pm 1.05$ & 0.6 \\
\hline P-value ${ }^{\text {b }}$ & $<0.001$ & $<0.001$ & & $<0.001$ & $<0.001$ & & $<0.001$ & $<0.001$ & \\
\hline
\end{tabular}

${ }^{\text {ap}}$-value between treatment groups.

${ }^{b} \mathrm{P}$-value between paired means. 
Considering moderate pockets $(5 \mathrm{~mm})$, a mean PPD reduction of $2.42 \pm 0.53 \mathrm{~mm}$ for the test group and $2.00 \pm 0.00 \mathrm{~mm}$ for the control group at the 6 months examination was observed. The differences between the groups were not statistically significant $(\mathrm{P}=0.38)$. PPD reduction for patients with deep pockets $(6-7 \mathrm{~mm})$ was statistically significant $(\mathrm{P}=0.006)$ between the groups at 6 months follow-up (Table 2).

The mean CAL gain in the test group was $2.0 \pm 0.64 \mathrm{~mm}$ and $1.13 \pm 1.05 \mathrm{~mm}$ in the control group (Table 1). The observed differences between the baseline and 6 months were found to be statistically significant $(\mathrm{P}<0.001)$ in the both groups. However, significantly greater $(\mathrm{P}=0.001)$ reduction in mean $\mathrm{CAL}$ was demonstrated in the test group (Table 1).

No statistically significant difference $(P=0.12)$ was observed between groups for moderate pockets (5 $\mathrm{mm}$ ) at the 6 months examination (Table 2). A mean CAL gain of $1.42 \pm 0.53 \mathrm{~mm}$ for the test group and $0.50 \pm 1.37 \mathrm{~mm}$ for the control group was observed. For the patients with deep pockets $(6-7 \mathrm{~mm})$, statistically significant difference $(\mathrm{P}=0.000)$ was observed between groups in $\mathrm{CAL}$ gain at the 6 months examination $(2.17 \pm 0.57 \mathrm{~mm}$ and $1.29 \pm 0.95 \mathrm{~mm}$ for the test and control groups, respectively) (Table 2).

The mean increase in REC was $1.03 \pm 1.15 \mathrm{~mm}$ in the test group and $1.16 \pm 1.05 \mathrm{~mm}$ in the control group at 6 months examination. A statistically significant increase in REC was found in the both groups $(\mathrm{P}<0.001)$ (Table 1). However, no statistically significant difference was found during the increase in REC between the test and control groups $(\mathrm{P}=0.643)$.

The test group presented a greater proportion of sites with PPD reduction of $3 \mathrm{~mm}$ and $4-5 \mathrm{~mm}$ i.e. $70 \%$ and $20 \%$ respectively, than the control group $(53.3 \%$ and $0 \%$ respectively). While, the control group presented a greater proportion of sites with PPD reduction of $2 \mathrm{~mm}$ i.e. $46.7 \%$ than in the test group (10\%) (Figure 1).

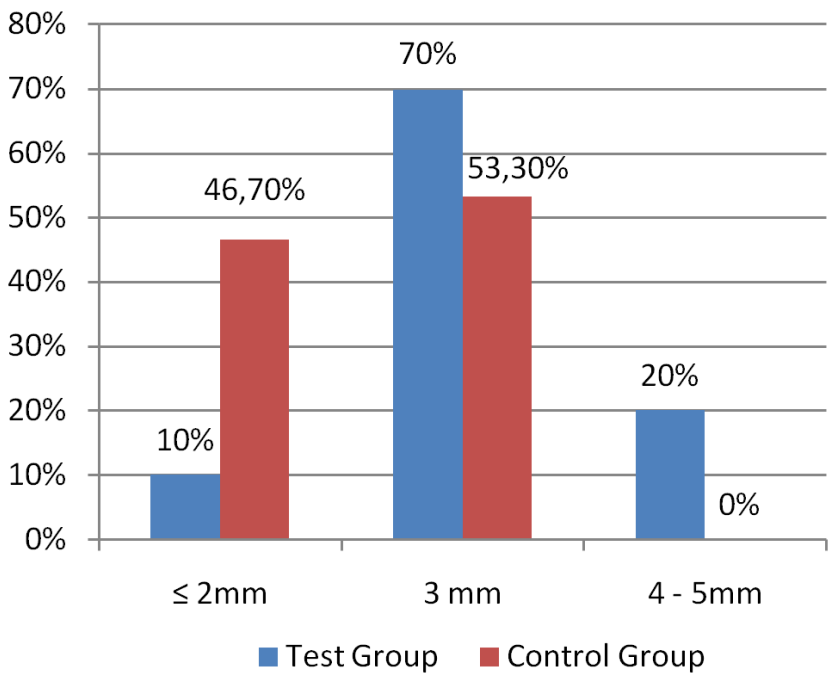

Figure 1. Mean percentage of sites presenting periodontal probing depth reduction in test and control groups at the 6 months examination.

A greater proportion of sites presenting CAL gain of $3 \mathrm{~mm}$ were observed in the test group (80\%) compared to the control group (30\%). While, the control group presented a greater proportion of sites with CAL gain of $1 \mathrm{~mm}$ and $2 \mathrm{~mm}$ i.e. $35 \%$ each than the test group i.e. $3.3 \%$ and $16.6 \%$ respectively (Figure 2 ).

\section{DISCUSSION}

This clinical trial was performed to examine the clinical efficacy of subgingivally delivered controlled drug therapy of doxycycline hyclate $10 \%$ (Atridox ${ }^{\circledR}$, CollaGenx Pharmaceuticals, Inc., Newtown PA, USA) in conjunction with a non-surgical treatment of periodontal pockets affected by the chronic periodontitis. During the active treatment, doxycycline hyclate $10 \%$ was well tolerated with no side effects observed in any of patients. At the baseline, the investigated parameters on

Table 2. Mean values of periodontal probing depth (PPD) reduction and clinical attachment level (CAL) gain for moderate and deep pockets in the test and control group patients at the 6 months examination

\begin{tabular}{|c|c|c|c|c|c|}
\hline Parameters & Pocket depth & Test & Control & $\begin{array}{c}\text { Difference } \\
(\text { Mean } \pm \text { SD }[\mathrm{mm}])\end{array}$ & P-value \\
\hline \multirow{2}{*}{$\begin{array}{c}\text { PPD Reduction } \\
(\text { Mean } \pm \text { SD }[\mathrm{mm}])\end{array}$} & $\begin{array}{l}\text { Moderate pockets } \\
(5 \mathrm{~mm})\end{array}$ & $2.42 \pm 0.53$ & $2.00 \pm 0.00$ & $0.42 \pm 0.21$ & $0.38^{\mathrm{b}}$ \\
\hline & $\begin{array}{c}\text { Deep pockets } \\
(6-7 \mathrm{~mm})\end{array}$ & $3.21 \pm 0.95$ & $2.50 \pm 0.51$ & $0.71 \pm 0.22$ & $0.006^{\mathrm{a}}$ \\
\hline \multirow{2}{*}{$\begin{array}{c}\text { CAL Gain } \\
(\text { Mean } \pm \text { SD }[\mathrm{mm}])\end{array}$} & $\begin{array}{c}\text { Moderate pockets } \\
(5 \mathrm{~mm})\end{array}$ & $1.42 \pm 0.53$ & $0.50 \pm 1.37$ & $0.92 \pm 0.56$ & $0.42^{\mathrm{b}}$ \\
\hline & $\begin{array}{c}\text { Deep pockets } \\
(6-7 \mathrm{~mm})\end{array}$ & $2.17 \pm 0.57$ & $1.29 \pm 0.95$ & $0.88 \pm 0.23$ & $0.000^{\mathrm{a}}$ \\
\hline
\end{tabular}

${ }^{\text {aS }}$ Statistically significant (Student's paired t-test, $\mathrm{P}<0.05$ ).

${ }^{\mathrm{b}}$ Statistically non significant (Student's paired t-test, $\mathrm{P}>0.05$ ). 


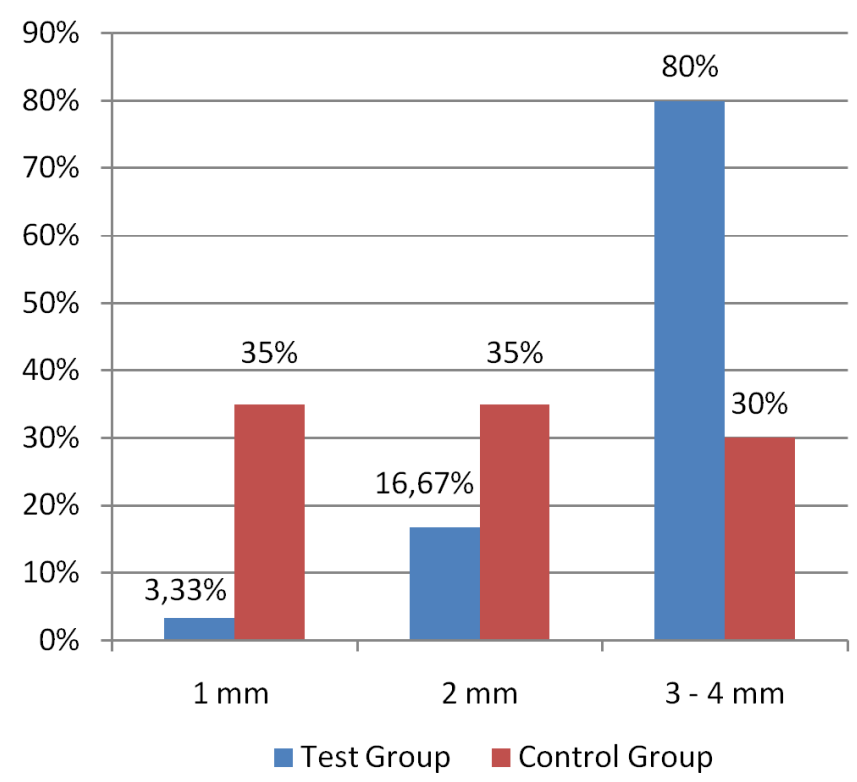

Figure 2. Mean percentage of sites presenting clinical attachment level gain in test and control groups at the 6 months examination.

the sites treated with SRP + doxycycline hyclate 10\% were similar to those of SRP + Placebo.

The adjunctive use of locally delivered antibiotics can provide additional benefit when compared to the conventional therapy $[\underline{3}, 14]$. The present study demonstrated significantly greater PPD reductions in the both groups. Similarly, at the 6 months examination significant gain of CAL was observed in the test $(2.0 \pm 0.64 \mathrm{~mm})$ and control group $(1.13 \pm 1.07 \mathrm{~mm})$ compared to the baseline with significantly higher $(\mathrm{P}<0.001) \mathrm{CAL}$ gain of $0.87 \pm 0.22 \mathrm{~mm}$ in the test group compared to the control group.

The difference in PPD reductions observed was apparently higher than the other studies with similar experimental design $[10,11]$. Recently, Gupta et al. [15] in a study reported a reduction of $2.73 \pm 1.33 \mathrm{~mm}$ PPD at 3 months following the administration of doxycycline hyclate $10 \%$ as an adjunct to mechanical therapy in the treatment of chronic periodontitis. The authors also reported a gain of $1.73 \pm 0.90 \mathrm{~mm}$ in CAL after the 3 months. Similarly, Garrett et al. $[\underline{16}, 17]$ compared two multicenter studies findings of the locally delivered doxycycline hyclate $10 \%$ as a monotherapy with SRP and showed similar results for either PPD reduction $(1.3 \mathrm{~mm}$ and $0.9 \mathrm{~mm}$, respectively) or CAL gain ( $0.8 \mathrm{~mm}$ and $0.7 \mathrm{~mm}$, respectively). The results obtained in the present study were somewhat better in comparison with previous studies. The possible reasons were the exclusion of smokers from the study and stringent plaque control throughout the follow-up period by patients. Furthermore, it is well established that the organized structure of biofilm can block proper diffusion or even inactivate the pharmacological agents subgingivally. Thus, previous biofilm removal could favour greater efficacy of the antibiotic against subgingival pathogens, explaining the differences favouring the adjunctive therapy found in the present study.

Considering both moderate and deep pockets, a difference of $2.42 \pm 0.53 \mathrm{~mm}$ and $3.21 \pm 0.95 \mathrm{~mm}$ respectively were observed at the 6 months period for PPD reduction and $1.42 \pm 0.53 \mathrm{~mm}$ and $2.17 \pm 0.57 \mathrm{~mm}$ for CAL gain at the 6 months examination both favouring the test group. However, considering deep sites, the present study showed significant differences in PPD reduction $(0.71 \pm 0.22 \mathrm{~mm}, \mathrm{P}=0.006)$ and $\mathrm{CAL}$ gain $(0.88 \pm 0.23 \mathrm{~mm}, \mathrm{P}=0.000)$ favouring the test group. Indeed, residual subgingival deposits are frequently observed after conventional instrumentation in the deep sites [18]. The use of the local drug delivery is beneficial as it will provide the concentrated amount of drug in the pockets, which is of the greater significance when the pockets are deeper and the subgingival mechanical instrumentation alone cannot be relied upon. In addition, the proportion of sites showing attachment gain of $3 \mathrm{~mm}$ in the present study was significantly greater for the treatment with doxycycline hyclate $10 \%+$ SPR $(80 \%)$ than for the control group (30\%). Similarly, the proportion of sites showing PPD reduction of $3 \mathrm{~mm}$ was significantly greater for the treatment with doxycycline hyclate $10 \%$ (70\%) than for the control group (53.3\%). A greater proportion of sites showing PPD reduction and CAL gain could represent an advantage in maintenance therapy, limiting the need for surgical procedures to fewer non-responding sites and eventually extending the period between recall visits.

The local delivery system may have provided bactericidal levels of the doxycycline hyclate $10 \%$ to the periodontal pocket, which resulted in a reduction of the subgingival bacterial bioburden which led to the positive clinical outcomes. The sustained levels achievable with the locally delivered doxycycline provided bactericidal concentrations (i.e., MIC 90s) among the vast majority of microorganisms present in the biofilm and may have been able to adequately penetrate the depth of the subgingival biofilm [19]. An additional benefit of the local drug delivery system is that it is relatively simple procedure to perform and moreover, patient acceptance is better as compared to invasive procedures such as the surgical treatment.

\section{CONCLUSIONS}

From the analysis of results it can be concluded that the use of doxycycline hyclate $10 \%$ as an adjunct to scaling and root planing provides more favourable and statistically significant reductions in periodontal probing depth and gains in clinical attachment level compared 
to scaling and root planing. The use of doxycycline hyclate $10 \%$ as an adjunct to the scaling and root planing may provide additional benefits to the periodontal treatment, especially for the treatment of deep pockets. The present study had few limitations as well. The small sample size has limited statistical analysis of results and a long term analysis is needed to determine the stability of results. Most importantly microbial culture tests would have more comprehensively demonstrated the beneficial effects of doxycycline hyclate $10 \%$.

Further studies are needed to determine which type of the patients and lesions will benefit most from the incorporation of subgingivally delivered controlled release doxycycline as an adjunct to the non-surgical periodontal therapy.

\section{ACKNOWLEDGMENTS AND DISCLOSURE STATEMENTS}

The authors report no conflicts of interest related to this study.

\section{REFERENCES}

1. Cobb CM. Non-surgical pocket therapy: mechanical. Ann Periodontol. 1996 Nov;1(1):443-90. Review. [Medline: 9118268 ] [doi: 10.1902/annals.1996.1.1.443]

2. Palcanis KG. Surgical pocket therapy. Ann Periodontol. 1996 Nov;1(1):589-617. Review. [Medline: 9118272] [doi: 10.1902/annals.1996.1.1.589]

3. Wennström JL, Newman HN, MacNeill SR, Killoy WJ, Griffiths GS, Gillam DG, Krok L, Needleman IG, Weiss G, Garrett S. Utilisation of locally delivered doxycycline in non-surgical treatment of chronic periodontitis. A comparative multi-centre trial of 2 treatment approaches. J Clin Periodontol. 2001 Aug;28(8):753-61. English, French, German. [Medline: 11442735] [doi: 10.1034/j.1600-051X.2001.280806.x]

4. Goodson JM: Drug delivery. In: Perspectives on oral antimicrobial therapeutics. Chicago: American Academy of Periodontology; 1987. p. 61-78.

5. Goodson JM. Pharmacokinetic principles controlling efficacy of oral therapy. J Dent Res. 1989;68 (Special Issue):1625-32.

6. Stoller NH, Johnson LR, Trapnell S, Harrold CQ, Garrett S. The pharmacokinetic profile of a biodegradable controlledrelease delivery system containing doxycycline compared to systemically delivered doxycycline in gingival crevicular fluid, saliva, and serum. J Periodontol. 1998 Oct;69(10):1085-91. Erratum in: J Periodontol 1999 Feb;70(2):238. [Medline: 9802705]

7. Goodson JM, Cugini MA, Kent RL, Armitage GC, Cobb CM, Fine D, Fritz ME, Green E, Imoberdorf MJ, Killoy WJ, et al. Multicenter evaluation of tetracycline fiber therapy: II. Clinical response. J Periodontal Res. 1991 Jul;26(4):371-9. [Medline: 1831505] [doi: 10.1111/j.1600-0765.1991.tb02076.x]

8. Williams R, Paquette D, Offenbacher S, Van Dyke T, Lang N, Cochran D, Page R, McDonald G, Santucci E, Lessem J. Locally delivered microencapsulated minocycline (MPTS) in the treatment of moderate adult periodontitis. J Dent Res 2001 Feb;80(2). (AADR Abstract \#1481).

9. Walker CB, Pappas JD, Tyler KZ, Cohen S, Gordon JM. Antibiotic susceptibilities of periodontal bacteria. In vitro susceptibilities to eight antimicrobial agents. J Periodontol. 1985 Nov;56(11 Suppl):67-74. [Medline: 3866054$]$

10. Polson AM, Garrett S, Stoller NH, Bandt CL, Hanes PJ, Killoy WJ, Harrold CQ, Southard GL, Duke SP. Multi-center comparative evaluation of subgingivally delivered sanguinarine and doxycycline in the treatment of periodontitis. I. Study design, procedures, and management. J Periodontol. 1997 Feb;68(2):110-8. [Medline: 9058327]

11. Polson AM, Garrett S, Stoller NH, Bandt CL, Hanes PJ, Killoy WJ, Southard GL, Duke SP, Bogle GC, Drisko CH, Friesen LR. Multi-center comparative evaluation of subgingivally delivered sanguinarine and doxycycline in the treatment of periodontitis. II. Clinical results. J Periodontol. $1997 \mathrm{Feb}$;68(2):119-26. [Medline: 9058328]

12. Turesky S, Gilmore ND, Glickman I. Reduced plaque formation by the chloromethyl analogue of victamine C. J Periodontol. 1970 Jan;41(1):41-3. [Medline: 5264376]

13. Mühlemann HR. Psychological and chemical mediators of gingival health. J Prev Dent. 1977 Jul-Aug;4(4):6-17. [Medline: 275483]

14. Newman HN. Periodontal therapeutics--a viable option? Int Dent J. 1998 Jun;48(3):173-9. [Medline: 9779096]

15. Gupta R, Pandit N, Aggarwal S, Verma A. Comparative evaluation of subgingivally delivered $10 \%$ doxycycline hyclate and xanthan-based chlorhexidine gels in the treatment of chronic periodontitis. J Contemp Dent Pract. 2008 Nov 1;9(7):25-32. [Medline: 18997913]

16. Garrett S, Johnson L, Drisko CH, Adams DF, Bandt C, Beiswanger B, Bogle G, Donly K, Hallmon WW, Hancock EB, Hanes P, Hawley CE, Kiger R, Killoy W, Mellonig JT, Polson A, Raab FJ, Ryder M, Stoller NH, Wang HL, Wolinsky LE, Evans GH, Harrold CQ, Arnold RM, Southard GL, et al. Two multi-center studies evaluating locally delivered doxycycline hyclate, placebo control, oral hygiene, and scaling and root planing in the treatment of periodontitis. J Periodontol. 1999 May;70(5):490-503. [Medline: 10368053] [doi: 10.1902/jop.1999.70.5.490] 
17. Garrett S, Adams DF, Bogle G, Donly K, Drisko CH, Hallmon WW, Hancock EB, Hanes P, Hawley CE, Johnson L, Kiger R, Killoy W, Mellonig JT, Raab FJ, Ryder M, Stoller N, Polson A, Wang HL, Wolinsky LE, Yukna RA, Harrold CQ, Hill M, Johnson VB, Soouthard GL. The effect of locally delivered controlled-release doxycycline or scaling and root planing on periodontal maintenance patients over 9 months. J Periodontol. 2000 Jan;71(1):22-30. [Medline: 10695935] [doi: 10.1902/jop.2000.71.1.22]

18. Walker SL, Ash MM. A study of root planning by scanning electron microscopy. Dent Hyg (Chic). 1976 Mar;50(3):109-14. [Medline: 1074692]

19. Walker CB, Godowski KC, Borden L, Lennon J, Nangó S, Stone C, Garrett S. The effects of sustained release doxycycline on the anaerobic flora and antibiotic-resistant patterns in subgingival plaque and saliva. J Periodontol. 2000 May;71(5):768-74. [Medline: 10872958] [doi: 10.1902/jop.2000.71.5.768]

\section{To cite this article:}

Deo V, Ansari S, Mandia S, Bhongade B. Therapeutic Efficacy of Subgingivally Delivered Doxycycline Hyclate as an Adjunct to Non-surgical Treatment of Chronic Periodontitis.

J Oral Maxillofac Res 2011;2(1):e3

URL: http://www.ejomr.org/JOMR/archives/2011/1/e3/v2n1e3ht.pdf

doi: $10.5037 /$ jomr.2011.2103

Copyright (C) Deo V, Ansari S, Mandia S, Bhongade B. Accepted for publication in the JOURNAL OF ORAL \& MAXILLOFACIAL RESEARCH (http://www.ejomr.org), 20 December 2010.

This is an open-access article, first published in the JOURNAL OF ORAL \& MAXILLOFACIAL RESEARCH, distributed under the terms of the Creative Commons Attribution-Noncommercial-No Derivative Works 3.0 Unported License, which permits unrestricted non-commercial use, distribution, and reproduction in any medium, provided the original work and is properly cited. The copyright, license information and link to the original publication on (http://www.ejomr.org) must be included. 